\title{
Review on Food Safety Crisis Governance
}

\author{
Xu Zu ${ }^{1}$, Yide Duan ${ }^{1,}$, Yue Qiu ${ }^{2}$ \\ ${ }^{1}$ Business School, Sichuan Agricultural University, Chengdu, 611830, China \\ ${ }^{2}$ Graduate School, Chengdu University of TCM, Chengdu, 611137, China \\ *Corresponding author
}

Keywords: Food Safety Crisis, Prevention, Response

\begin{abstract}
Based on the perspective of the enterprise, this paper summarizes the research results of food safety crisis management from three aspects: internal and external crisis incentives prevention strategies, as well as coping behaviors, coping subjects and coping effects, and finds that domestic and foreign scholars specifically target the responsible entities. The research results of crisis management strategies are insufficient, and the set of enterprise prevention and response strategies for food safety crisis needs to be systematic and comprehensive.
\end{abstract}

\section{Introduction}

The evolution of food safety risks into a crisis is a "destined" nightmare for food companies and the food industry. The rapid development of mobile internet, the diversification of channels for information dissemination and the speed indexing have made food safety risks more likely to evolve into crises, posing a huge threat to food companies, the food industry, and even the state. The food safety crisis can be defined as: occasional foods that contain threats (or potential threats) to the health of consumers, toxic or hazardous substances, or quality problems such as substandard nutrition, have been widely exposed and concerned and have (or may be) given to enterprises Or an event that has a huge negative impact on society. It is imperative for food companies under the mobile Internet to manage the food safety crisis, and it is imminent. In order to effectively manage the food safety crisis, this study summarizes the research results of previous scholars on the governance of food safety crisis from the perspective of prevention and response based on the enterprise perspective.

\section{Research on the Prevention Strategy of Food Safety Crisis Enterprises}

The food safety crisis enterprise prevention strategy refers to the company's ability to actively identify the problem risk factors and analyze the source of the risk and fully prepare for the crisis situation to prevent the crisis from occurring or reduce the losses caused by the crisis. In the past, scholars have relatively little research on corporate defense strategies. The research results mainly focus on the prevention and prevention strategies of the internal and external crisis incentives.

In terms of corporate internal crisis prevention strategies, the crisis prevention strategies proposed by domestic and foreign scholars from internal incentives are mainly concentrated in corporate social responsibility behaviors (Zhang \& Gao et al, 2015), social media communication (Rutsaert \& Pieniak, 2014), and sound standards system (Yang Jianshun) , 2014), improving production conditions and improving the internal management level of enterprises (Zhang Hongxia, An Yufa, 2013), etc., Zhang \& Gao et al (2015) found that corporate social responsibility behavior can effectively reduce the risk probability of food safety problems. And the degree of corporate social responsibility behavior positively affects the effect of risk management of food safety issues. Rutsaert \& Pieniak (2014) found that social media can convey easy-to-understand information to consumers as an effective communication platform, so that consumers can be responsible for corporate responsibility and prevent food safety crisis.

In terms of corporate external crisis incentive prevention strategies, domestic and foreign scholars' crisis prevention strategies proposed from outside enterprises are mainly focused on food supply chain monitoring and early warning (Xu and Qing, 2012), network public opinion 
monitoring and early warning ( $\mathrm{Li} \&$ Xiao et al, 2013), quality Protection Tracking (Zhang Hongxia, An Yufa, 2013) and risk information exchange among corporate members (Cui Baojun, Yu Weiping, 2015).

\section{Research on Corresponding Strategies of Food Safety Crisis Enterprises}

The food safety crisis enterprise response strategy refers to the fact that after the crisis, enterprises can reasonably use various resources and measures to curb the deterioration of the crisis as soon as possible and solve the negative effects brought by the crisis. The existing research results are concentrated in the research results of the product injury crisis coping strategy, which can be summarized into three aspects: coping behavior, coping subject and coping effect.

Coping strategies-response behaviors, the research on the crisis response behaviors can be summarized in three aspects: image restoration theory, situation crisis communication theory and market repair perspective:

Image restoration theory believes that the corporate image after the crisis depends mainly on consumer perception, not on the real situation of the crisis itself (Benoit, 1997), that is, regardless of the actual situation of the crisis, consumers only think that the enterprise should Responsible for crisis events, companies must adopt a response strategy as soon as possible to repair corporate image. Based on this, Benoit (1997) proposed four specific categories of 14 corporate image restoration behavior strategies, including five categories of strategies including denial, evasion of responsibility, reduction of offensive, corrective behavior, and inhibition of behavior. The denial strategy means that the company claims that it has never done anything wrong or blamed others for being responsible for the crisis, including simply denying and transferring the accusation; the evading responsibility strategy means that the company emphasizes lack of information or lack of ability to cause a crisis, or Emphasis on crisis events is an accident, including reasonable response, powerless control, accident, good purpose; reducing offensive strategy means that enterprises focus on transferring consumers' attention to crisis events, including support, differentiation, dilution, transcendence, counterattack, Compensating the victim's six behaviors; correcting behavior refers to the company's plan or commitment to solve existing problems to prevent the recurrence of the problem; the suppression behavior refers to the company's recognition and confession of mistakes, expression of remorse, apology and request for forgiveness. Kabak \& Irwin et al (1991) proposed that corporate coping behaviors can be divided into four types according to the level of effort after the crisis: denial, involuntary response, voluntary response, and very hard response. Bradford \& Garrett (1995) proposed five kinds of coping behaviors that did not respond, deny, justify, acknowledge the responsibility of the company for crisis events, and claimed that the crisis was reported untrue, that the crisis was serious, and that it was responsible. Coombs (2007) classifies crisis response behavior into seven categories: attack, denial, excuses, rationalization, catering, correction, and complete apology. Attacks, denials, excuses, and rationalization tend to resist orientation. Catering, correcting, and completely apologizing tend to conform. . Xu Heqing (2013) proposed the five major coping strategies: the truth investigation strategy, the perfect management strategy, the interactive communication strategy, the loss compensation strategy and the accountability strategy after the food safety crisis.

Scholars who construct corporate crisis response behavior based on the theory of situational crisis communication often believe that the company can make the crisis response behavior achieve the predicted effect by coping with the specific crisis situation. Coombs \& Holladay (1996) based on the responsibility of crisis incidents: If the crisis responsibility is internal and accidental, the company should emphasize the unintentional to relieve the pressure of responsibility. If the crisis responsibility is internal and wrong, the company should apologize. And repair the corporate image as soon as possible. Ryals (2005) pointed out that enterprises should defend their externally capable events, and should deny externally incapable events. For those incapable of controlling within the enterprise, they should be justified and have internal control over their capabilities. As well as uncertain events, companies should recognize and use measures such as apologies and recalls. With the richness and deepening of research results, Coombs (2007) classifies three types of crisis events: 
victimized, accidental, and preventable based on liability attribution, and proposes that in a victimized crisis scenario, enterprises can adopt a dilution strategy or a denial strategy. In an unexpected crisis scenario, companies can adopt a reshaping strategy or a denial strategy. In a preventable crisis scenario, companies should adopt a reshaping strategy. Founder et al. (2011) proposed that in the face of indisputable product injury incidents, corporate response behavior should include firm denial, forced recall, voluntary recall and active responsibility, and in the face of solvable product injury crisis, corporate response should include correction Measures, positive clarification, ignorance, and counter-rebuttal.

Research on corporate crisis response based on the perspective of market remediation focuses on how to restore consumer trust. Xie\&Peng (2009) found that restoring consumer trust depends mainly on the informational, emotional and functional remediation strategies adopted by the company. The information remediation strategy emphasizes the positive perception of consumers' ability to the enterprise, and the emotional remediation strategy emphasizes To shape the goodwill image of the integrity and honesty of the company, the functional restoration strategy emphasizes the ability image of the company in terms of production quality improvement. Dong Yani (2010) divided the three types of market repair strategies: maintenance, defect improvement and function enhancement. Among them, the function-enhanced strategy has the best effect on consumer trust repair. Enterprises can adopt product-persuasive advertisement and corporate image advertisement in the function-enhanced strategy.

Coping strategies - In dealing with the subject, Siomkos \& Kurzbard (1994) divided the crisis response subject into two categories: the corporate subject and the external subject. Founder (2007) divided the crisis response subjects into four categories: enterprises, governments, experts, and industries through case analysis of product injury crisis, and found that governments, experts, and industry respond to behaviors to improve consumer attitudes and purchase intentions. The effect is better.

Coping strategies - coping effects, after the crisis, companies often adopt a variety of crisis response behaviors from the "denial" to "active responsibility" strategies. Studies have shown that companies' active responsibility often achieves a positive response, but denial often has a greater impact on consumers' negative perceptions (Siomkos \& Kurzbard, 1994). At the same time, the crisis response effect is also affected by many factors. When the severity of the crisis is high, the timeliness of the strategy is the most critical factor (Vassilikopoulou \& Lepetsos et al, 2009). Other major research results also show that corporate entities prioritize external entities to make consumers feel the sense of corporate responsibility (Shrivastava \& Siomkos, 1989), and corporate social responsibility behavior positively affects corporate crisis response (Lin \& Chen et al, 2011).

\section{Research review and Entry Point of This Study}

From the literature review, there is still research space in the corporate governance strategy system of food safety crisis under mobile internet (see Table 1). The existing research results rarely combine mobile internet, Internet of things, and intelligence to explore a corporate governance strategy system for building food safety crisis. Domestic and foreign scholars specifically target the corporate crisis management strategies of responsible entities. The research on prevention and response strategies for food safety crisis needs to be systematic and comprehensive.

Table 1 related research opportunities and entry points for this study

\begin{tabular}{|c|c|c|}
\hline Research areas & Existing research & Research opportunity \\
\hline Crisis governance strategy & $\begin{array}{l}\text {-Enterprise prevention } \\
\text { strategy: prevention of internal } \\
\text { crisis and external incentives } \\
\text {-Corporate coping strategies: } \\
\text { focus on behaviors, coping } \\
\text { with subjects and coping } \\
\text { effects }\end{array}$ & $\begin{array}{l}\text { - Food enterprise crisis prevention } \\
\text { strategy results mainly focus on } \\
\text { internal incentives and systemic } \\
\text { shortcomings } \\
\text {-Food business crisis response } \\
\text { strategy is limited to emergency } \\
\text { communication }\end{array}$ \\
\hline
\end{tabular}




\section{Acknowledgements}

Fund Project: Fund Project: Key Research Base of Philosophy and Social Science of Sichuan Province--Southwestern Poverty Reduction and Development Research Center Key Project (SCP1802); Sichuan Agricultural University Social Science Key Project (2018ZD04); Sichuan Province Philosophy and Social Science Key Research Base--Sichuan Agriculture Featured Brand Development and Communication Research Center General Project (CAB1810)

\section{References}

[1] Zhang D, Gao Y, Morse S. Corporate social responsibility and food risk management in China; a management perspective [J]. Food Control, 2015, 49:2-10.

[2] Rutsaert P, Pieniak Z, Áine Regan, et al. Social media as a useful tool in food risk and benefit communication? A strategic orientation approach [J]. Food Policy, 2014, 46(3): 84-93.

[3] Yang Jianshun. On Food Safety Risk Exchange and Legal Operation of Production Operators [J]. Jurist, 2014(1): 43-55.

[4] Zhang Hongxia, An Yufa. Sources and prevention strategies of food safety risks in food production enterprises_C Content analysis based on food safety incidents [J]. Economic Issues, 2013(5): 73-76.

[5] Xu Heqing. Research on Brand Enterprise Image Maintenance in Food Safety Accidents_-A Survey Based on Consumer Perspective [J]. East China Economic Management, 2013(2): 97-102.

[6] Li H, Xiao H, Qiu T, et al. Food safety warning research based on internet public opinion monitoring and tracing [C]. International Conference on Agro-Geoinformatics. 2013:481-484.

[7] Cui Baojun, Yu Weiping. Characteristics, Causes and Governance of Industry Unspoken Regular Product Injury Crisis_- Taking the Food Industry as an Example [J]. Social Science Front, 2015(8): 44-53.

[8] Benoit W L. Image repair discourse and crisis communication [J]. Public Relations Review, 1997, 23(2): 177-186.

[9] Kabak B, Irwin W, Siomkos, et al. Replacement after a Product Harm Crisis [J]. Industrial Management, 1991.

[10] Bradford J L, Garrett D E. The Effectiveness of Corporate Communicative Responses to Accusations of Unethical Behavior [J]. Journal of Business Ethics, 1995, 14(11): 875-892.

[11] Coombs W T. Protecting Organization Reputations During a Crisis: The Development and Application of Situational Crisis Communication Theory [J]. Corporate Reputation Review, 2007, 10(3): 163-176.

[12] Coombs W T, Holladay S J. Communication and Attributions in a Crisis: An Experimental Study in Crisis Communication [J]. Journal of Public Relations Research, 1996, 8(4): 279-295.

[13] Ryals L. Making Customer Relationship Management Work: The Measurement and Profitable Management of Customer Relationships [J]. Journal of Marketing, 2005, 69(4): 252-261.

[14] Fang Zheng, Yang Yang, Jiang Minghua, et al. Study on the impact of solvable product injury crisis coping strategies on brand equity: the role of regulatory variables and mediator variables [J]. Nankai Management Review, 2011, 14(4): 69- 79.

[15] Xie Y, Peng S. How to repair customer trust after negative publicity: The roles of competence, integrity, benevolence, and forgiveness [J]. Psychology \& Marketing, 2009, 26(7): 572-589.

[16] Dong Yani. Research on Market Recovery Strategy of Product Injury Crisis [J]. 商业研究, 2010 (1): 23-27. 
[17] Siomkos G J, Kurzbard G. The Hidden Crisis in Product-harm Crisis Management [J]. European Journal of Marketing, 1994, 28(2): 30-41.

[18] Fang Zheng. Research on the Concept, Classification and Coping Style of Product Injury Crisis [J]. Productivity Research, 2007(4): 63-65.

[19] Vassilikopoulou A, Lepetsos A, Siomkos G, et al. The importance of factors influencing product-harm crisis management across different crisis extent levels: A conjoint analysis[J]. Journal of Targeting, Measurement and Analysis for Marketing, 2009, 17(1): 65-74.

[20] Shrivastava P, Siomkos G. Disaster Containment Strategies [J]. Journal of Business Strategy, 1989, 10(5): 26-30.

[21] Lin CP, Chen SC, Chiu CK, et al. Understanding Purchase Intention During Product-Harm Crises: Moderating Effects of Perceived Corporate Ability and Corporate Social Responsibility [J]. Journal of Business Ethics, 2011, 102(3): 455. 